\title{
Clean up of contaminated sediments of the Taranto harbour by stabilization/solidification treatment
}

\author{
F. Cangialosi, G. Intini, L. Liberti, M. Notarnicola, T. Pastore \\ \& F. Tazzoli \\ Department of Environmental Engineering and Sustainable Development, \\ Technical University of Bari, Italy
}

\begin{abstract}
The most widely used procedure for reducing the contamination effects of marine sediments is the dredging and disposal of material in controlled landfills. This method is becoming impracticable because it is increasingly difficult to find adequate space. This study was carried out to design an effective treatment method for heavy metal contaminated sediments using stabilization/solidification $(\mathrm{S} / \mathrm{S})$ technology. In particular, experimental investigation on a laboratory scale has been carried out to highlight the effect of inorganic pollutants (copper, nickel and lead) on physico-chemical properties and the leaching behaviour of cement-based solidified materials. To better understanding the $\mathrm{S} / \mathrm{S}$ process, both artificially spiked and field samples of Taranto harbour sediments contaminated by heavy metals were treated with different kinds of cement and water/cement/sediment ratios. The results of laboratory tests indicated that sediment to be treated requires an increase of the water/cement ratio, due to its remarkable content of fine fraction. A good immobilization of copper, lead and nickel after only seven days of curing, due to high $\mathrm{Ph}$ values (8-9) and the percentage of silica (approx. $60 \%$ in weight) in harbour sediment limiting metal leaching from the solidified matrix was observed. In conclusion the cement based S/S technology seems to be effective in treating marine sediments contaminated by heavy metals and is promising for large scale application.
\end{abstract}

Keywords: contaminated sediments, stabilization/solidification, heavy metals, leaching tests. 


\section{Introduction}

Stabilization and solidification $(\mathrm{S} / \mathrm{S})$ is known as one of the most popular technologies for treating and disposing of a broad range of contaminated media like toxic or hazardous wastes [1]. Generally, for inorganic wastes the hazard is related to heavy metal content. The U.S. Environmental Protection Agency (EPA) considers $\mathrm{S} / \mathrm{S}$ as a proven treatment technology for the management of industrial hazardous wastes. Also in recent EU directives about solid waste management $\mathrm{S} / \mathrm{S}$ processes play an important role because in the near future only inert or stabilized waste could be landfilled [2].

The treatment process involves mixing hazardous waste with hydraulic binders and it is aimed at safe landfilling or re-use as construction material. Various types of cement and pozzolanic additives such as coal fly ash, lime, blast-furnace slag and similar materials are mostly used as stabilizing matrix [3]. Heavy metal ions are immobilized through chemisorption, precipitation, surface adsorption, "capturing" inside the matrix, chemical incorporation or with a combination of the mentioned processes [4]. S/S is an effective treatment for a wide variety of organic and inorganic soil contaminants, and consequently often used for remediation purposes. Furthermore, the contaminated material can be treated in-situ or ex-situ as already segregated waste or excavated material [5].

Recently cement-based $\mathrm{S} / \mathrm{S}$ processes are being employed to treat marine sediment contaminated by heavy metals, dioxins, PCBs and PAHs $[6,7,8]$.

In this paper, different types of hydraulic binders and water/cement ratios were investigated for the S/S treatment of artificial and field samples of contaminated harbour sediments, analyzing the leachability of heavy metals from the final cementitious material to assess the effectiveness of the process.

\section{Materials and methods}

\subsection{Sediment samples}

The Taranto Sea is located in the southern part of Italy on the Ionian Sea and it is made of two basins: the Mar Grande and the Mar Piccolo. Representative samples of marine contaminated sediment were collected from material dredged in Taranto's harbour in the Mar Piccolo. Uncontaminated samples were collected in the external basin of Mar Grande.

The sediment samples were analysed to assess the main physico-chemical characteristics and the degree of contamination. Particle size distribution was determined using dry and wet sieving techniques. Sediment $\mathrm{pH}$ was determined with a Multilane P4 pH-meter (WTW Instruments) by equilibrating $20 \mathrm{~g}$ of sediment with $20 \mathrm{~mL}$ of distilled/deionised water on an end-over-end shaker. Total organic matter content was measured by drying sediment sample in a $50{ }^{\circ} \mathrm{C}$ oven for $24 \mathrm{~h}$ followed by ignition at $500{ }^{\circ} \mathrm{C}$ for $6 \mathrm{~h}$. Losses resulting from ignition were determined gravimetrically. 
Sediment pozzolanic activity was evaluated following the Italian UNI EN 196/5 test, which consist of a comparison between the degree of $\mathrm{OH}$ - quantity in a standard solution at the saturation point and the solution of interest, after a determined period of contact time. If the quantity of $\mathrm{OH}-$ in the interest solution is under the saturation curve the test is positive.

The adsorbed water limit of the sediment was evaluated in order to establish the minimum quantity of water necessary to reach the saturation point. The key parameters obtained were the shrinkage limit and the shrinkage ratio. The analysis was carried out following the Italian UNI 10014 method.

\subsection{Sediment artificial contamination}

The uncontaminated sediment coming from external basin (Mar Grande) was subjected to a procedure of contaminant spiking to be able to investigate a series of process parameters and verify the removal efficiency of the S/S technique on a real matrix, field and artificially contaminated, instead of totally synthetic samples. In a typical spiking procedure the sediment was passed through a screen, dried and then saturated in a $1 \mathrm{~L}$ glass container with the spike solution in a slurry-phase [9]. Artificial contamination was carried out with three selected metals: lead $(\mathrm{Pb})$, copper $(\mathrm{Cu})$, nickel $(\mathrm{Ni})$. The selected metals used were pure $(99 \%)$ and were obtained from J. T. Baker. The metal solution was prepared by dissolving an established quantitative of pollutant in some $\mathrm{mL}$ of solvent, depending on the sediment sample quantity and the final concentration degree [9]. The spiking procedure involves a certain contact time and a chemical equilibrium depending on the final pollutants concentration. They were 550, 975 and $525 \mathrm{mg} / \mathrm{kg}$ for nickel, lead and copper respectively.

\subsection{Solidification/stabilization tests}

Cement is very suited as $\mathrm{S} / \mathrm{S}$ reagent for metal contaminants. In fact, it reduces the mobility of inorganic compounds by formation of insoluble hydroxides, carbonates, or silicates, and substitution of the metal into a mineral structure and physical encapsulation $[10,11]$. S/S treatment can also reduce the toxicity of some heavy metals by changes in valence state. Cements with different binders abilities were used during the tests: CEM I 32.5 R, CEM I $42.5 \mathrm{R}$ and the aluminous one.

As known, in the S/S tests the principal objective of the mixing is to reach the best interaction between cement and sediment in a homogeneous matrix. Different batch tests were carried out in order to mix together water, cement and contaminated sediment in an optimal ratio. In a typical mixing operation, in the first step cement was mixed with half part of water for 1 minute, than was added the sediment and the rest of water in two steps in order to maximize the homogeneity of the mixture. The ratio sediment/cement and water/sediment was equal to $3: 1$ and 0.5 respectively. The mixture obtained was dried naturally. After 3, 7, 14, and 28 days the concentration of toxic metal ions in leachate solutions was determined by atomic absorption spectrometry. 


\subsection{Leaching tests}

The leaching test relies on extracting the sample with a diluted organic acid (acetic acid), thus simulating conditions of co-disposed organic waste such as in a municipal landfill. The test procedure, according to Italian regulation for landfill disposal of waste [12], was applied on the original and S/S treated samples in order to evaluated heavy metals and organic pollutants in the leachate. The test consists of 24 hours extraction procedure in continuous stirring with a 16 times ratio liquid/solid, under controlled $\mathrm{pH}(<5)$. After this period the liquid phase was separated from the solid and stored in controlled conditions until analysed.

The $\mathrm{pH}$ was monitored during the leaching test with acetic acid in order to assess the sediment ability to balance the adding of acid solution. The $\mathrm{pH}$ was measured with electronic pH-meter (Multilane P4) with a frequency of 15 minutes for a total time of 24 hours.

\subsection{Analytical methods}

Chemical analyses were performed for inorganic and organic pollutants on solid samples (original and S/S treated) and liquid samples (leachate). The sediment sample was digested [13] and the metal ions analysed by AA spectrometry (Varian Spectra). Organic contaminants like PAHs and PCBs were extracted applying USEPA SW846/3550b method [14] and determined after purification with EPA-8310 and EPA-8082 method respectively. Analyses of the sediment extracts were carried out with a gas-chromatograph (Varian CP-3800) equipped with an electron capture detector (ECD) for the PCBs determination. PAHs were analysed with a HPLC system (Agilent Technologies).

\section{Results and discussion}

\subsection{Sediment characterization}

Table 1 shows the state of the contamination in the field contaminated sediment samples.

As for grain size distribution of the sediment, the fine fraction is $76 \%$ of total weight. The sediment is constituted by the $24 \%$ of sand, $46 \%$ of silt, and $30 \%$ of clay, according to the $0.063 \mathrm{~mm}$ dimensional limit for the sand and $0.002 \mathrm{~mm}$ for the silt. The water content in the sediment was almost the same: $24 \%$ for the field contaminated sample and $22 \%$ for the spiked one. Both samples did not show any pozzolanic activities.

As for the adsorbed water limit, because of its grain size distribution, the sediment adsorbs almost $40 \%$ of water in weight. This amount is assumed as an overplus in the calculation of water ratio during the stabilization/solidification process.

Leachate data of untreated sediment samples are reported in Table 2. Low metals concentrations were detected: copper and nickel are near the instrumental resolution in spite of high concentration of these metals in solid matrix. 
Table 1: $\quad$ Field sediment contamination.

\begin{tabular}{|c|c|c|}
\hline & Contaminants & $\begin{array}{c}\text { Concentration } \\
\text { (mg/kg dry weight) }\end{array}$ \\
\hline \multirow{8}{*}{ 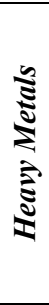 } & As & 160 \\
\hline & $\mathrm{Cd}$ & 3 \\
\hline & $\mathrm{Cr}$ & 32 \\
\hline & $\mathrm{Cu}$ & 768 \\
\hline & $\mathrm{Fe}$ & 31270 \\
\hline & $\mathrm{Hg}$ & 26 \\
\hline & $\mathrm{Ni}$ & 79 \\
\hline & $\mathrm{Pb}$ & 2897 \\
\hline \multirow{12}{*}{$\underset{\Sigma}{\Sigma}$} & Anthracene & 2.00 \\
\hline & Fluoranthene & 0.69 \\
\hline & Pyrene & 15.14 \\
\hline & Chrysene & 8.12 \\
\hline & Phenanthrene & 7.49 \\
\hline & Benzo(a)pyrene & 12.18 \\
\hline & Benzo(a)Antracene & 0.25 \\
\hline & Benzo(e) pyrene & 0.01 \\
\hline & Benzo $(b+k)$ fluoranthene & 11.09 \\
\hline & Dibenzo(a,h)anthracene & 0.07 \\
\hline & Total hydrocarbons & 1597 \\
\hline & Total PCBs & 30 \\
\hline
\end{tabular}

Table 2: $\quad$ Leaching behaviour of untreated spiked sediment samples (mg/L).

\begin{tabular}{|l|c|c|c|}
\hline Sediment Sample & $\mathbf{C u}$ & $\mathbf{N i}$ & $\mathbf{P b}$ \\
\hline Field & 0.37 & 0.28 & 0.87 \\
\hline Spiked & 0.41 & 0.4 & 3 \\
\hline
\end{tabular}

Table 3: $\quad$ Mineralogical constituents of untreated spiked sediment samples.

\begin{tabular}{|c|c|}
\hline Mineral & (\%) \\
\hline $\mathrm{CaCO}_{3}$ & 25.11 \\
\hline $\mathrm{SiO}_{2}$ & 62.19 \\
\hline $\mathrm{Albite}$ & 0.75 \\
\hline $\mathrm{MgO}$ & 1.25 \\
\hline $\mathrm{Al}_{2} \mathrm{O}_{3}$ & 3.24 \\
\hline $\mathrm{KCl}$ & 0.35 \\
\hline K-feldspar & 0.57 \\
\hline Wollastonite & 5.38 \\
\hline Metallic iron & 1.16 \\
\hline TOTAL & $\mathbf{1 0 0}$ \\
\hline
\end{tabular}

This behaviour is due to a particular mineralogical characteristic of the Taranto harbour sediment: because of its high silica content (see Table 3). In fact, the sediment is able to keep high the $\mathrm{pH}$ in the solution balancing the addiction of acetic acid during the leaching test (buffering effect). 
The trend of the $\mathrm{pH}$ during a leaching process is very important considering that adsorption is the core factor in metal stabilization within a solid matrix and adsorption capacity is related with alkaline value of the $\mathrm{pH}$ [15].

Figure 1 shows the $\mathrm{pH}$ values of untreated spiked samples versus leaching time. A certain quantity of acetic acid $(50 \mathrm{~mL})$ has been added between 28 and 39 minutes during test. $\mathrm{pH}$ value, after a decrease until 5.2 in this period, reincreased to about 8 in approximately 2 hours, buffering acid addition and limiting the leaching of metals.

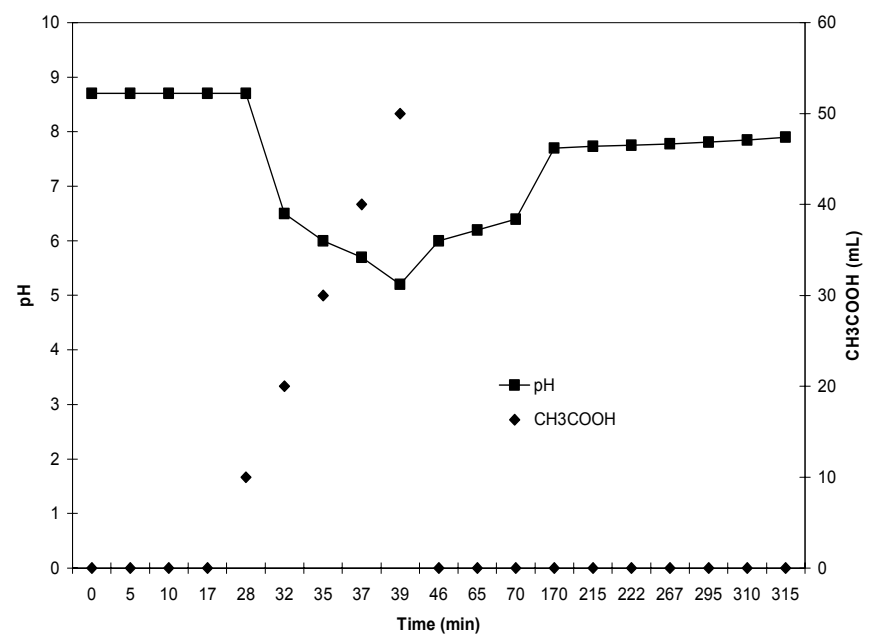

Figure 1: $\quad \mathrm{pH}$ trend during leaching test of untreated spiked sediment samples.

\subsection{Leaching behaviour of stabilised/solidified products}

Metals concentration in leachate of S/S-treated spiked sediment samples cured at different times $(3,7,14$ and 28 days) is shown in Figure 2. CEM I $32.5 \mathrm{R}$ cement, sediment/cement ratio (3:1) and water/cement ratio $(0.5)$ were used for the $\mathrm{S} / \mathrm{S}$ process.

All the pollutants (in particular lead) highlight a concentration decrease during the time. Obviously the best results have been obtained after 28 days, when cement hydration products formation was almost completed immobilizing metals and improving water-resistance of the solidified sample. Because of the main changes in the leachability in the first 7 days, this time was chosen for further investigation.

Figure 3 shows leachate data after 7 days of curing of spiked samples S/Streated with 3 different cement types: CEM I $32.5 \mathrm{R}$, CEM I $42.5 \mathrm{R}$ and aluminous cement.

Figure 4 shows results of leachate analyses for the field contaminated sediment stabilized/solidified with the same three cement types. These results 
confirm the worsening of leaching behaviour with aluminous cement and highlight an increase with the $42.5 \mathrm{R}$ type for all the pollutants.

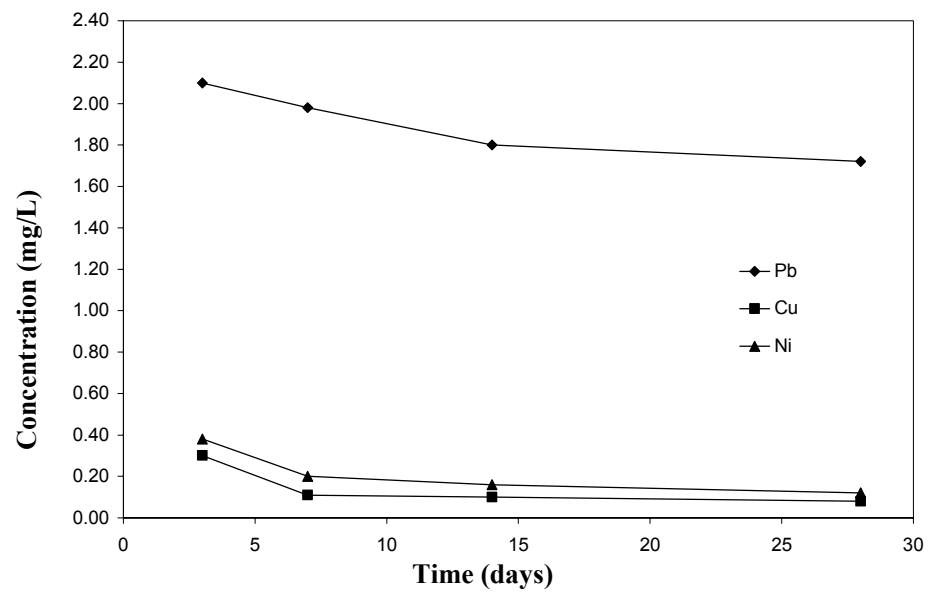

Figure 2: Leaching behaviour of S/S-treated spiked sediment samples cured at different times.

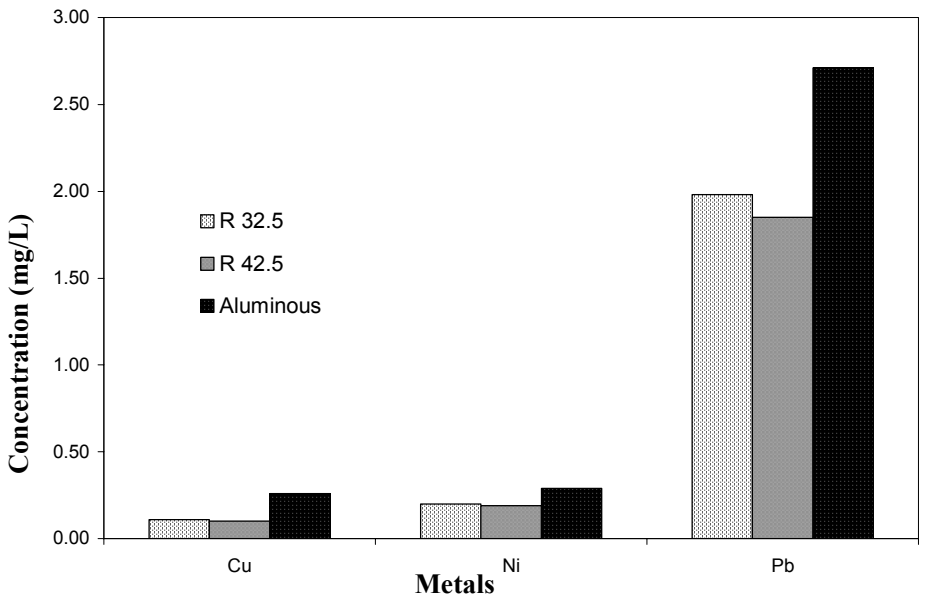

Figure 3: Leaching behaviour of $\mathrm{S} / \mathrm{S}$ spiked sediment samples treated with different cements ( 7 days curing).

\section{Conclusions}

In this paper the feasibility of cement-based $\mathrm{S} / \mathrm{S}$ treatment of Taranto harbour contaminated sediments has been assessed. On the basis of the experimental 
results obtained in the conditions investigated, the following conclusions can be summarised:

- heavy metals investigated (nickel, copper and lead) have shown low concentration values in leaching tests of untreated sediment samples in spite of their high concentration in the solid matrix, probably due to an acid buffering capability of the high silica content of sediment.

- A significant decrease in metals leaching occurred for S/S-treated sediment samples with 7 days of curing.

- CEM I 42.5 R cement, compared with 32,5 R and aluminous ones, has shown the best performance in $\mathrm{S} / \mathrm{S}$ process for both spiked and field contaminated sediments.

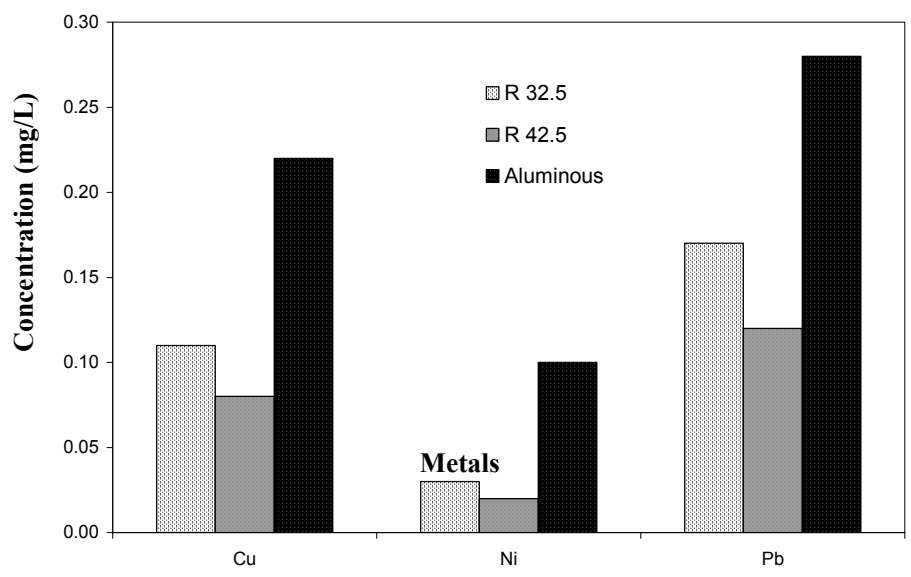

Figure 4: Leaching behaviour of $\mathrm{S} / \mathrm{S}$ field sediment samples treated with different cements ( 7 days curing).

Further investigations are necessary to assess the influence of organic pollutants, such as PCBs and PAHs, on the stabilization/solidification process of marine contaminated sediments.

\section{References}

[1] Mayers, T.E. \& Eappi, M.E., Laboratory evaluation of stabilization/solidification technology for reducing the mobility of heavy metals in New Bedford Harbor superfund site sediment Stabilization of Hazardous Radioactive and Mixed Wastes, 2nd edn. ASTM pub., Philadelphia, PA, pp. 304, 1992.

[2] Gougar, M.L.D., Scheetz, B.E. \& Roy, D.M., Ettringite and C-S-H Portland Cement Phases for Waste Ion Immobilization: A Review, Waste Management, 16(4), pp. 295-303, 1996. 
[3] Higgins, D.D., Kinuthia, J.M. \& Wild, S., Soil Stabilisation using LimeActivated GGBS, Proc. 6th CANMET/ICI Int. Conf. on Fly ash, Silica fume, Slag and Natural Pozzolans in Concrete. Editor: Malhotra V.M., 1998.

[4] Nocun-Wczelik, W. \& Malolepszy, J., Study on the Immobilization of Heavy Metals in Cement Paste - C-S-H Leaching Behaviour, Proc. of the 10th ICCC, Göteborg, Sweden, 4 (4iv043), pp. 8, 1997.

[5] Conner, J. R., Recent Findings on Immobilisation of Organics as Measured by Total Constituent Analysis, Waste Management, 1995.

[6] Benjamin, M.M. \& Leckie, J.D., Adsorption of Metals at Oxide Iinterfaces: Effects of the Concentrations of Adsorbate and Competing Metals (Chapter 16). Contaminants and Sediments, Volume 2: analysis, Chemistry, Biology, Edited by R.A. Baker, Ann Arbor, MI: Ann Arbor Science Publishers, Inc., 1980.

[7] Cullinane, M.J., Contaminated dredged material. Control, treatment and disposal practices. New Jersey, USA, 1990.

[8] Loest, K. \& Wilk, C.M., Brownfield Reuse of Dredged New York Harbor Sediment by Cement-based Solidification/Stabilization, Proc. of the 91st Annual Meeting \&Exhibition, Air and Waste Management Association, 1998.

[9] Technical Manual: Methods for Collection, Storage, Manipulation of Sediments for Chemical and Toxicological Analyses, USEPA, 2000. http://EPA/waterscience/cs/collection.htm

[10] Adaska, W.S., Solidification and Stabilization of Wastes Using Portland Cement, Portland Cement Association, EB071 2nd Edition, Skokie, IL., 1998.

[11] Bhatty, J.I., Stabilization of Heavy Metals in Portland Cement, Silica Fume/Portland Cement and Masonry Cement Matrices, RP348, Portland Cement Association, Skokie, IL.1999.

[12] Analytical Methods for Sludge. Vol. 3(64), Rome. IRSA-CNR, 1984.

[13] Italian Standard Methods for the Analyses of Sediments, ICRAM, 2003.

[14] Tests Methods for Evaluating Solid Waste, $3^{\text {rd }}$ Edition, Update III, U.S. GPO, Washington, DC., USEPA SW-846, 1995.

[15] Kleiv, R. A. \& Sandvik, K. L., Using tailings as heavy metals adsorbents - the effect of buffering capacity, NTNU, 2000. 